\title{
Laminar burning velocities of a renewable e-fuel: formic acid and its mixtures with $\mathrm{H}_{2}$ and $\mathrm{CO}_{2}$
}

S. Mani Sarathy ${ }^{1 *}$, Pierre Brequigny ${ }^{2}$, Amit Katoch ${ }^{1}$, A.M. Elbaz ${ }^{1}$, William L. Roberts ${ }^{1}$, Robert

W. Dibble ${ }^{1}$, Fabrice Foucher ${ }^{2}$

${ }^{1}$ King Abdullah University of Science and Technology, Clean Combustion Research Center, Physical Sciences and Engineering Division, Thuwal, Kingdom of Saudi Arabia

${ }^{2}$ Univ. Orléans, INSA-CVL, PRISME, EA 4229, F45072, Orléans, France

Corresponding Author:

S. Mani Sarathy

4700 King Abdullah University of Science and Technology

Clean Combustion Research Center

Al Kindi Bldg 5 Room 4222

Thuwal 23955-6900, Saudi Arabia

E-mail: mani.sarathy@kaust.edu.sa

\section{Supplementary Material}




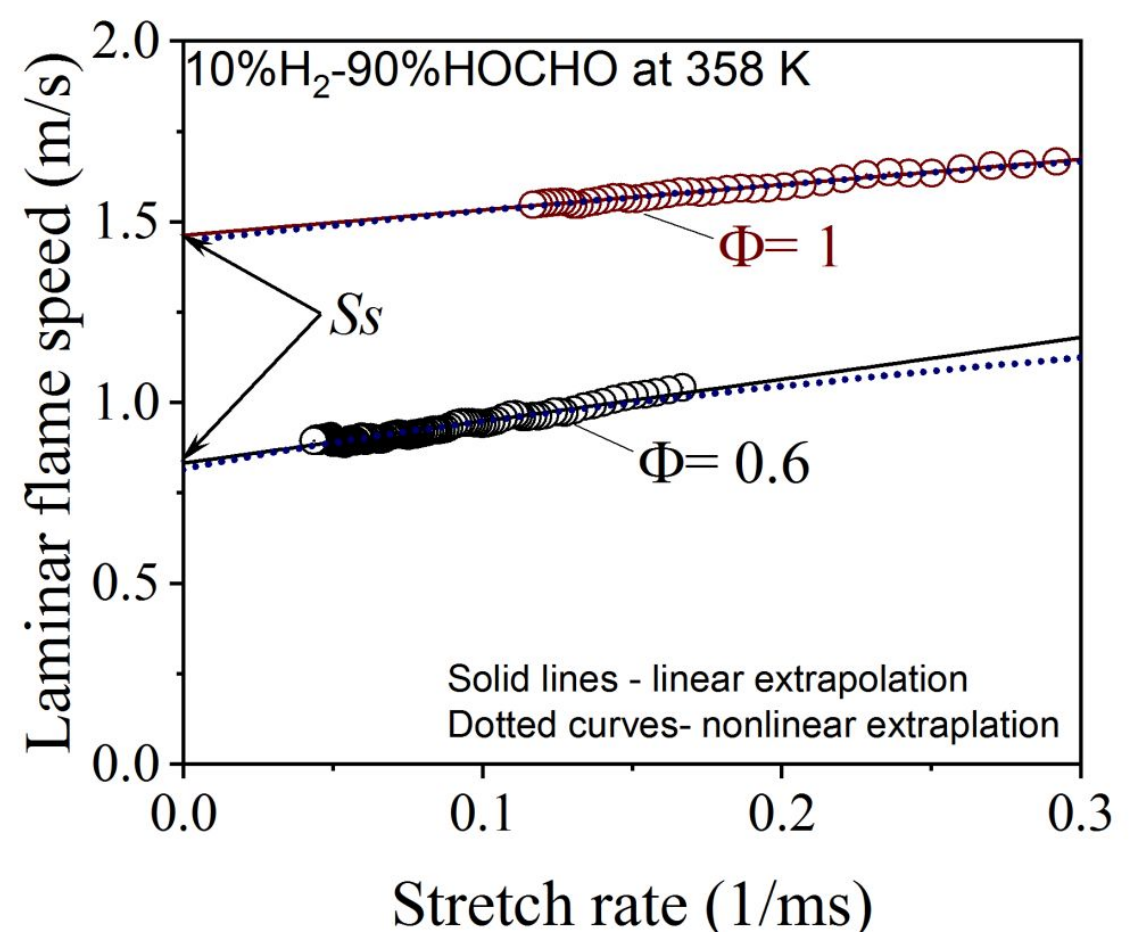

Figure S1 - Laminar flame speed versus stretch rate for selected laminar flame experiments conducted at KAUST. The figure shows the linear correlation (solid lines) and nonlinear extrapolation (dotted lines) between flame speed stretch rate. 


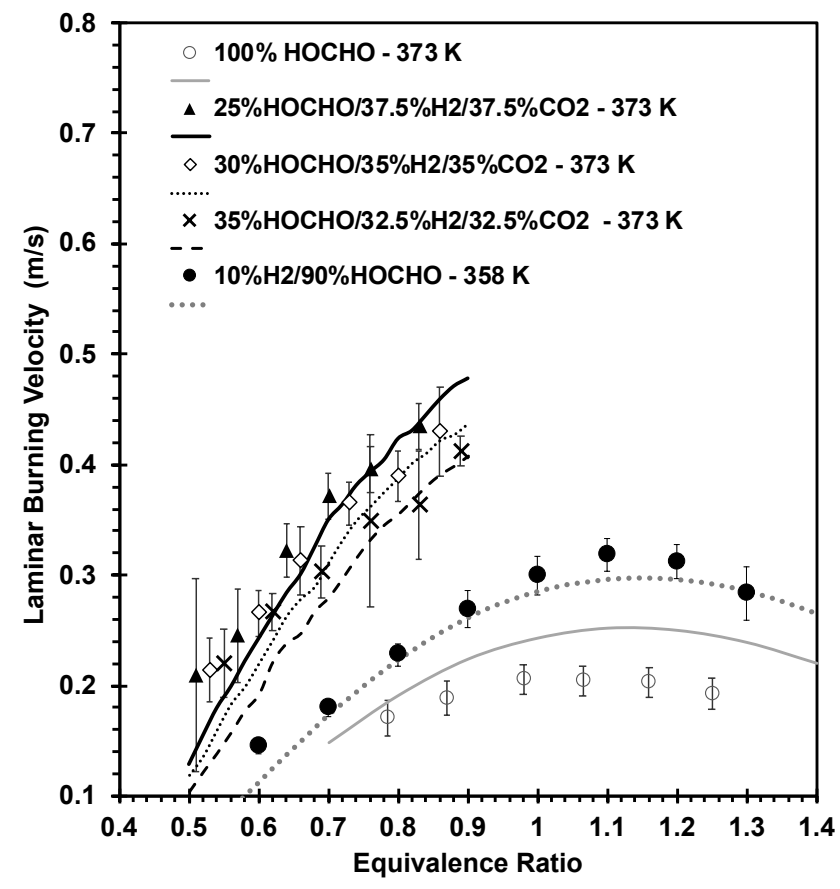

Figure 2 - LBV vs. equivalence ratio at 1 bar and 373K for various $\mathrm{HOCHO} / \mathrm{H} 2 / \mathrm{CO} 2 /$ air blends and $358 \mathrm{~K}$ for $10 \% \mathrm{H} 2 / 90 \% \mathrm{HOCHO} /$ air blend. Symbols are experimental data and lines are simulations using the Marshall and Glarborg model. 